\title{
"Baratura y clase". El discurso publicitario de la tienda A la Ciudad de Londres en la prensa gráfica. Buenos Aires hacia fines del siglo XIX
}

Resumen: El artículo analiza discursos publicitarios de A la Ciudad de Londres, la primera gran tienda de la ciudad de Buenos Aires. El trabajo traza los principales rasgos de la Buenos Aires del último tercio del siglo XIX: una sociedad cosmopolita que crecía y se diversificaba acompañada de un mercado interno en desarrollo, alimentado, principalmente, de artículos importados de Europa. En este contexto observamos y analizamos el fenómeno de las grandes tiendas, particularmente la primera tienda departamental de Buenos Aires; nos concentramos, específicamente, en los diferentes tipos de publicidad de esta tienda publicados en la prensa gráfica, en los que buscamos identificar las estrategias utilizadas para atraer clientes y crear necesidades.

Palabras clave: consumo, grandes tiendas, publicidad, moda, prensa ilustrada.

\section{"Cheapness and class". The advertising discourse of the A la Ciudad de Londres store in the press in late 19th century Buenos Aires}

Abstract: This article analyzes the advertising discourses of A la Ciudad de Londres, the first department store in Argentina's capital, Buenos Aires. The article traces the main characteristics of late 19th century Buenos Aires: a cosmopolitan society that grew and diversified, with an internal market in full swing, propelled mainly by imported goods from Europe. In this context we observe and analyze the phenomenon of the department stores, focusing specifically in the different types of advertisements, and the strategies employed to attract clients and create needs.

Keywords: consumption, department stores, advertising, fashion, press.

\section{"Barato e clássico”. Os discursos publicitários na imprensa gráfica da grande loja A la Ciudad de Londres em fins do século XIX, em Buenos Aires}

Resumo: 0 artigo analisa os anúncios publicitários da loja, A la Ciudad de Londres, a primeira grande loja de Buenos Aires. 0 trabalho traça as principais características de Buenos Aires no último terço do século XIX: uma sociedade cosmopolita que crescía e se diversificava acompanhada de um mercado interno em pleno desenvolvimento, o qual era caracterizado pela importação de produtos europeus. Nesse contexto observamos e analisamos o fenômeno das grandes lojas, especificamente a primeira grande loja de departamentos de Buenos Aires. 0 estudo concentrou-se nos diferentes tipos de anúncios dessa loja publicados na imprensa gráfica, nos quais, procuramos identificar as estratégias utilizadas para atrair clientes e criar necessidades.

Palavras-chave: consumo, grandes lojas, publicidade, moda, imprensa.

Cómo citar este artículo: Teresita Garabana y Cecilia Moreyra, "'Baratura y clase'. El discurso publicitario de la tienda A la Ciudad de Londres en la prensa gráfica. Buenos Aires hacia fines del siglo XIX", Trashumante. Revista Americana de Historia Socia/13 [2019]: 6-29.

DOI: 10.17533/udea.trahs.n13a01

Fecha de recepción: 5 de marzo de 2018

Fecha de aprobación: 12 de julio de 2018

Teresita Garabana: Doctoranda en Historia de la Universidad Nacional de San Martín y becaria del Consejo Nacional de Investigaciones Científicas y Técnicas [CONICET].

Correo electrónico: trst12@gmail.com

Cecilia Moreyra: Doctora en Historia por la Universidad Nacional de Córdoba. Investigadora asistente del Consejo Nacional de Investigaciones Científicas y Técnicas [CONICET]. Profesora asistente de la Universidad Nacional de Córdoba.

Correo electrónico: ceci_moreyra@hotmail.com 


\title{
"Baratura y clase". El discurso publicitario de la tienda A la Ciudad de Londres en la prensa gráfica. Buenos Aires hacia fines del siglo XIX
}

\author{
Teresita Garabana y Cecilia Moreyra
}

\section{Introducción}

En este artículo analizamos discursos publicitarios de A la Ciudad de Londres,

Ela primera tienda departamental de la ciudad de Buenos Aires, hacia finales del siglo XIX; período de notable crecimiento demográfico, urbano y económico en el que las prácticas de consumo comenzaron a distanciarse de las formas tradicionales de comprar y vender. De esta manera, las nuevas dinámicas de compra-venta trascendieron el estricto intercambio comercial e involucraron otras prácticas, decisiones, deseos y necesidades. En este marco, la publicidad constituyó un espacio para la comunicación entre productores, vendedores, medios, lectores, consumidores y objetos, y se erigió en instrumento privilegiado para la construcción de una clientela a la cual destinar la oferta de productos. Mediante el lema "baratura y clase" expresado en la publicidad gráfica de A la Ciudad de Londres se enfatizaban dos cualidades esenciales de los productos ofrecidos: bajo precio y elegancia. Aunque podrían pensarse como contradictorias, estas características intentarían definir uno de los sectores sociales al que se destinaban los productos: los sectores medios, aún en formación. Consustancial a la construcción del consumidor fue también la transmisión de saberes específicos: saber comprar, saber usar, en definitiva, saber consumir. De este modo, junto con los diferentes objetos se vendían también ideas y prácticas.

Analizar el discurso publicitario de esta gran tienda posibilita la comprensión de las nuevas dinámicas de compra-venta. Optamos por enfocarnos en la prensa escrita, dado que era el canal privilegiado para anuncios comerciales. Este discurso publicitario en la prensa escrita emerge en un contexto de proliferación de publicaciones periódicas (revistas) en Argentina, que fue de la mano de crecientes niveles de alfabetización.

Tradicionalmente investigado desde la historia económica, el fenómeno del consumo es también un objeto de la historia cultural, y es esta la perspectiva que adoptamos en este trabajo. Seguimos así el camino señalado por Fernando Rocchi, 
pionero en la historia del consumo en la Argentina moderna, cuyo trabajo ofrece una visión integral del fenómeno en el que entran en juego el proceso de industrialización del país, los cambios en la economía de exportación y la publicidad, todo ello vinculado a las trasformaciones políticas y sociales de la época. ${ }^{1}$

Dentro de un mercado capitalista cada vez más internacionalizado, Argentina ocupaba una posición de productora y exportadora de materia prima y alimentos y, al mismo tiempo, consumidora de bienes importados de la Europa industrializada. Asimismo, el creciente fenómeno inmigratorio, especialmente a partir de la década de 1880, significó no solo el crecimiento, sino también la diversificación de la población de Buenos Aires. Este crecimiento demográfico, sumado al económico y a las acciones tendientes a modernizar la ciudad explican la proliferación de diversas casas de negocio, entre las cuales se destacaron las grandes tiendas: establecimientos de capitales extranjeros que vendían productos importados -inicialmente textiles, ya fueran géneros o ropa hecha, y luego otros productos - a precio fijo en locales en los que la gente podía entrar, mirar y tocar sin la necesidad de comprar.

Para el análisis propuesto consultamos las publicaciones La Perla, El Cosmopolita y El Mosquito, resguardadas en la Biblioteca Nacional Mariano Moreno. La revista La Perla, se autodefinía como literaria, aunque también producía contenidos sobre moda y crónicas sociales. Se consultaron los 34 números disponibles y se encontraron avisos de la gran tienda en 14 de ellos. El Cosmopolita, por su parte, era un periódico quincenal de la sociedad de dependientes, cuyo propósito era "abogar por la solidaridad de todos los hombres" y los intereses del órgano que representaba. Se examinaron los 42 números disponibles en los cuales se localizaron avisos de la tienda en 20 de ellos. Estas publicaciones, así como la mayoría de sus contemporáneas, aseguraban su subsistencia mediante la suscripción, aunque incorporaban publicidad a fin de incrementar sus ganancias. Sin embargo, La Perla y El Cosmopolita fueron de las pocas publicaciones anteriores a 1880 que incluían publicidad en sus páginas. En cuanto al periódico El Mosquito, autodefinido como "periódico satírico" se revisaron los 154 números disponibles entre 1880 y 1882, entre los que identificamos 12 publicidades de la gran tienda, cada una, única en su especie.

Cabe señalar que ninguna de las colecciones se encuentra completa, por lo que un análisis cuantitativo carece de sentido; por ello, nos enfocamos en una indagación de carácter cualitativo. Del corpus consultado, seleccionamos la publicidad que manifiesta indicios de cambios en las prácticas de consumo; esto es, transformaciones en las formas de vender y comprar y en el proceso de comunicación entre productores, vendedores y consumidores. Los avisos fueron analizados teniendo en cuenta las tipografias utilizadas, el tamaño y proporción dentro de la página, la iconografia de las imágenes —en los casos de los avisos ilustrados - y la relación entre estas y el texto.

1. Fernando Rocchi, "Consumir es un placer: la industria y la expansión de la demanda en Buenos Aires a la vuelta del siglo pasado”, Desarrollo Económico 37.148 (1998): 533-558. 
Entre la publicidad que analizaremos se reconocen dos grandes formas de anunciar para vender: los avisos tradicionales y los modernos. ${ }^{2}$ Los primeros avisos de A la Ciudad de Londres, de tipo tradicional, se registran hacia 1878; los de tipo moderno, por su parte, con una alta carga visual como carácter distintivo, se observan, por ejemplo, en la revista El Mosquito entre 1880 y 1882. Lejos de clasificaciones taxativas donde formas modernas sucederían automáticamente a las tradicionales, los avisos comerciales de la época, en general, y de la tienda A la Ciudad de Londres, en particular, son heterogéneos; es decir, coexisten ambas formas. Se trata de un período de transición en el que la imagen adquiere un peso mayor frente a la disminución del texto y los recursos tipográficos.

\section{Buenos Aires en el último tercio del siglo XIX: transformaciones sociales, cosmopolitismo y mercado interno}

Dentro del mercado capitalista mundial, en franco crecimiento durante el siglo XIX, Argentina cumplía el rol de exportadora de bienes primarios producidos en el espacio pampeano, específicamente: lana, cereales, lino, carne congelada ovina y animales en pie. La exportación de productos primarios constituyó el motor del crecimiento económico argentino de finales del siglo XIX; sin embargo, lejos de recibir pasivamente la riqueza generada en el campo, Buenos Aires fue una pieza relevante dentro de la economía agroexportadora, con lo que proveía bienes y servicios para un mercado interno en permanente expansión. ${ }^{3}$ Desde finales de la década de 1860 la población de Buenos Aires venía aumentando en forma sostenida gracias a las oleadas inmigratorias; tan es así, que hacia 1870 la mitad de su población estaba compuesta por nacidos en Europa, ${ }^{4}$ tendencia que se acentuó, aún más, a partir de 1880 .

Con el desarrollo del modelo agroexportador la población de Buenos Aires no solo se triplicó, sino que se volvió en promedio dos veces y medio más rica que a mediados del siglo. Llegó a tener en los últimos años del siglo XIX un ingreso per cápita que se asemejaba más al de Inglaterra o Estados Unidos que al de otros países latinoamericanos. ${ }^{5}$ Esta visión de conjunto no debe soslayar la desigual distribución de esa riqueza: mientras algunas familias fueron capaces de adquirir terrenos en la pampa húmeda, lo cual redundó en un enriquecimiento franco y vertiginoso, gran parte de los inmigrantes no conseguirían más que una habitación de alquiler

2. Tomamos esta distinción del análisis que realizan Paula Félix-Didier y Sandra Szir, quienes, no obstante, emplean el término "local" para designar la publicidad que en este trabajo denominamos "tradicional". Paula Félix-Didier y Sandra Szir "Ilustrando el consumo" (Comunicación presentada en el I Congreso Internacional de Teoría e Historia de las Artes del Congreso Argentino de Investigadores del Arte: Poderes de la imagen, Asociación de Amigos del Museo de Bellas Artes de Buenos Aires, 2001).

3. Roy Hora, Historia económica de la Argentina en el siglo XIX (Buenos Aires: Siglo XXI, 2010) 131.

4. Hora 129 .

5. Rocchi, "Consumir es un placer" 536. 
en un conventillo y trabajos informales mal pagos. Así, el Buenos Aires de esta época estará signado por la heterogeneidad de su población. En este contexto también se incrementó y diversificó la demanda de bienes y servicios que, sumada a una progresiva "europeización" de las costumbres y las pautas de consumo, estimuló las importaciones, así como ciertas condiciones que favorecieron el desarrollo de la producción local. La noción de europeización apunta a un imaginario que concebía a Europa - especialmente, Francia e Inglaterra - como modelo de progreso y civilización. Ideario de larga data que emerge de un rasero idealizado de las ciudades europeas en el que no cabía la imagen de la empobrecida y "atrasada" Europa rural. ${ }^{6}$ Por consiguiente, cabe aclarar que la población europea que migró a Argentina en el siglo XIX no necesariamente fue portadora de los cánones urbanos, dado que en su mayoría se trataba de familias italianas y españolas pobres, que cruzaban el Atlántico con la ilusión de mejorar su situación.

El crecimiento poblacional y económico que venimos describiendo impulsó transformaciones en el espacio urbano que otorgaron a Buenos Aires un aspecto elegante y europeo: se inauguró un sistema de tranvías a caballo; se construyeron distinguidos edificios públicos y privados; se extendió el alumbrado a gas y el empedrado de las calles, y se mejoraron los servicios de agua, recolección de basura y drenado. ${ }^{7}$ Los cambios demográficos, económicos y urbanos engendraron las condiciones para la proliferación de diversos negocios, muchos de los cuales se dedicaban a la venta de indumentaria. Para 1885 la Gran Guía de Buenos Aires daba cuenta de la existencia de más de 500 negocios de ropa, 17 casas importadoras de "paños y casimires", 62 casas introductoras de artículos para tiendas y mercerías, 25 depósitos de máquinas de coser, cerca de 100 modistas y más de 300 sastrerías. $^{8}$

Sumado a las transformaciones materiales, el proyecto de alfabetización buscó integrar a una numerosa y heterogénea población mediante la escolarización obligatoria, pública y gratuita. Este proceso formó un conjunto de ciudadanos capaces de consumir productos culturales que, anteriormente, quedaban circunscritos a las élites. Surgieron, entonces, un conjunto de publicaciones periódicas, en su mayoría ilustradas, que interpelaban a los ciudadanos y les ofrecían información, imágenes, ideas y productos nuevos. ${ }^{9}$ Junto a ellas, circulaban crónicas y periódicos

6. En la producción literario periodística de la Generación del 37 (grupo intelectual y político de mediados del siglo XIX entre los que destacan Domingo Faustino Sarmiento, Esteban Echeverría, Juan Bautista Alberdi) se plantea la imagen de una Europa (especialmente la noratlántica) moderna y "civilizada" como modelo a seguir para romper con el atraso que significaba la tradición colonial.

7. Hora 131-134.

8. Hugo Kunz y Cía, Gran guía de la Ciudad de Buenos Aires (Buenos Aires: Hugo Kunz y Cía, 1885) 908-927.

9. En 1882 Argentina se ubicaba en tercer lugar entre los países de mayor circulación de periódicos por habitante con un total de 224 títulos de diversa regularidad publicados en todo el país. Las publicaciones periódicas ilustradas multiplicaron su cantidad de títulos. Véase Sandra Szir, "Discursos, prácticas y formas culturales de lo visual. Buenos Aires 1880-1910", Travesías de la imagen. Historia de las artes visuales en la Argentina, vol. 1, eds. María Isabel Baldasarre y Silvia 
extranjeros que permitían a la población local el acceso a noticias, sucesos y modas europeos. Como consecuencia, tal como ya señalamos, Buenos Aires no solo experimentó cambios cuantitativos en su población, sino que la composición de la sociedad se vio transformada. Bien señaló Gino Germani que la inmigración llevó "a la virtual desaparición del tipo social nativo preexistente, a la vez que la destrucción de parte de la estructura social que le correspondía. En su lugar emergió un nuevo tipo, aún no bien definido, y una nueva estructura". ${ }^{10}$ Dentro de esta nueva estructura, que caracterizaría a lo que Fernando Devoto y Marta Madero llamaron "la Argentina plural", el problema de la ubicación social estaría en el centro de las preocupaciones. ${ }^{11}$ La conformación de las jerarquías sociales implicaba la auto identificación de cada grupo con referentes distintivos; la elevada posición social estaría dada según la cercanía que se tuviese respecto a los ideales de belleza, prestigio y elegancia establecidos como cánones. ${ }^{12}$ Pero el estatus social solo adquiría significado si se visibilizaba a través de pautas culturales, ritos, pasatiempos y consumos por medio de los cuales se forjaban lazos de pertenencia entre sus integrantes, al tiempo que se creaban límites y fronteras de admisión frente a otros grupos sociales. ${ }^{13}$ Así, desde fines del siglo XIX la alta sociedad de Buenos Aires experimentó una profunda transformación y, a diferencia de las élites de épocas anteriores, se caracterizó por un afán renovado de distinción y elegancia. ${ }^{14}$

Mientras la élite refinaba y europeizaba su estilo de vida, quienes se ubicaban por debajo de ella experimentaban transformaciones también intensas. La inmigración, la proliferación de los centros urbanos, la diversificación económica, la movilidad social y el avance de la alfabetización hicieron surgir sectores medios, todavía incipientes, entre los que predominaron los inmigrantes con valores de impronta burguesa como la respetabilidad, el ahorro y el esfuerzo. ${ }^{15}$ Hacia fines del siglo XIX vemos a la ciudad de Buenos Aires atravesada y constituida por cambios heterogéneos. Sin embargo, para esta época la conformación de un mercado interno se encuentra aún en proceso y la producción fabril, en general, así como el rubro textil, en particular, recién logran cifras significativas hacia 1890. En este sentido, es factible pensar que para 1880, cuando A la Ciudad de Londres ya se encuentra consolidada como gran tienda, todavía estamos en una etapa previa al

Dolinko (Buenos Aires: Editorial de la Universidad Nacional del Tres de Febrero, 2011) 65-94; Adolfo Prieto, El discurso criollista en la formación de la Argentina moderna (Buenos Aires: Editorial Sudamericana, 1988).

10. Gino Germani, Política y sociedad en una época de transición (Buenos Aires: Paidós, 1974) 11-31.

11. Fernando Devoto y Marta Madero, dirs., Historia de la vida privada en la Argentina, t. 2 (Buenos Aires:Taurus, 1999) 7-13.

12. Devoto y Madero 14-17.

13. Leandro Losada, La alta sociedad en la Buenos Aires de la Belle Époque. Sociabilidad, estilos de vida e identidades (Buenos Aires: Siglo XXI, 2008) 16-30.

14. Roy Hora y Leandro Losada, "Clases altas y medias en la Argentina, 1880-1930. Notas para una agenda de investigación”, Desarrollo Económico 50.200 (2011): 611-630.

15. Hora y Losada 623. 
consumo masivo que se despliega a principios del siglo XX. ${ }^{16}$ Más aun, nos preguntamos si fueron en las grandes tiendas, con sus renovadas formas de producción, compra y venta, donde emergieron los primeros atisbos de esa sociedad de consumo masivo.

\section{Lo tradicional y lo moderno: pequeñas y grandes tiendas}

En aquella Buenos Aires en proceso de “modernización” el comercio minorista de vestimenta no solo creció exponencialmente, sino que, como señalamos, se modernizó de la mano de las grandes tiendas. Negocios de este tipo surgieron en París alrededor de 1852, y de allí se extendieron hacia el resto de Europa, Estados Unidos y las principales ciudades de Latinoamérica. ${ }^{17}$ Según William Leach, las grandes tiendas y almacenes fueron fundamentales para el desarrollo de la economía capitalista, pues llevaron, concretamente, el capitalismo "moderno" a los hogares. ${ }^{18}$

Si bien el desarrollo de las grandes tiendas tuvo particularidades locales, es factible identificar aspectos comunes a todas: en primer lugar, el margen de ganancia sobre cada artículo era pequeño, compensado con un gran volumen de venta; en segundo lugar, los precios de los productos eran fijos y estaban claramente marcados; y, finalmente, cualquier persona podía entrar a la tienda y curiosear sin sentirse obligada a comprar. ${ }^{19}$ El surgimiento de este tipo de establecimiento comercial en Europa se vincula a la creciente producción fabril del período, es decir, que estos negocios estarían destinados a vender la prolífica producción de las industrias. Sin embargo, aunque los grandes almacenes parisinos hayan surgido como una respuesta directa a las fábricas, ${ }^{20}$ en Buenos Aires la situación fue diferente, puesto que la aparición de las primeras grandes tiendas —a mediados de la década de

16. Fernando Rocchi, "Inventando la soberanía del consumidor: publicidad, privacidad y revolución del mercado en la Argentina, 1860-1940", Historia de la vida privada en la Argentina, t. 2, dirs. Fernando Devoto y Marta Madero (Buenos Aires:Taurus, 1999) 301-321.

17. El surgimiento de las grandes tiendas en el mundo occidental fue objeto de estudio de varios historiadores. En Inglaterra, Bill Lancaster, The Department Store: A Social History (Leicester: Leicester University Press, 1995); Erika D. Rappaport, “The Halls of Temptation': Gender, Politics, and the Construction of the Department Store in Late Victorian London", The Journal of British Studies 35.1 (1996): 58-83. En Estados Unidos, William R. Leach, Land of Desire. Merchants, Power, and the Rise of a New American Culture (New York: Vintage Books, Random House, 1993); William R. Leach, "Transformations in a Culture of Consumption. Women and Department Stores, 1890-1925”, The Journal of American History 71.2 (1984): 319-342. Para América Latina, el caso mexicano es desarrollado por Steven B. Bunker, “'Consumers of Good Taste': Marketing Modernity in Northern Mexico, 1890-1910", Mexican Studies / Estudios Mexicanos 13.2 (1997): 227-269; y un análisis del caso chileno lo encontramos en el trabajo de Jacqueline Dussaillant Christie, Las reinas de Estado: consumo, grandes tiendas y mujeres en la modernización del comercio de Santiago (1880-1930) (Santiago: Pontificia Universidad Católica de Chile, 2011).

18. Leach, Land of Desire 20-24.

19. Richard Sennett, El declive del hombre público (Barcelona: Anagrama, 2011) 179.

20. Sennett 180. 
1870 - precedió al despegue de la industria textil nacional. ${ }^{21}$ Aunque la economía mostraba signos de inestabilidad - la unificación de la moneda nacional, por ejemplo, recién tuvo lugar en 1880 - daba a los inversores extranjeros la impresión de un futuro prometedor, ligado al modelo agroexportador.

Los grandes almacenes parisinos se caracterizaron por una constante y renovada oferta de artículos, que había que vender para volver a ofrecer la flamante producción; por ello, se estimulaba a los compradores a adquirir productos que probablemente no necesitaban. Una de las estrategias fue colocar escaparates en todas las plantas bajas de las grandes tiendas, y las mercancías visiblemente acomodadas se convirtieron en un espectáculo por derecho propio. ${ }^{22}$ Además, la tienda fue también un espacio de sociabilidad, ${ }^{23}$ donde las personas que la visitaban se movían, observaban y expresaban en función de aquello que deseaban comprar. ${ }^{24}$

En Buenos Aires, el Censo general de población de 1887 registró más de 700 casas de vestido. Como los establecimientos comerciales abarcaban y reunían ramos de comercio de distinta clase y género, se volvía compleja la clasificación por rubros: "es muy general en Buenos Aires, ver perfumerías en las cuales se expenden vinos y licores finos, así como trajes confeccionados en el extranjero, y mil objetos diversos de fantasía". ${ }^{25}$ Esto equivaldría a lo que desde mediados del siglo XIX era conocido como "tienda de novedades". En cuanto a los negocios dedicados a la venta de vestimenta, el censo las discrimina en "Roperías" en las cuales se vendía, generalmente al por mayor, ropa de fabricación nacional; "Ropavejerías", también conocidas como "cambalaches", se dedicaban a vender y comprar toda clase de artículos usados tales como ropa, muebles, armas, alhajas falsas, etc.; "Sombrererías" que, además de sombreros, solían vender ropa blanca, corbatas, bastones y otros artículos para hombre, y, finalmente, el rubro “Tiendas y mercerías", de muy variada envergadura, incluía a las denominadas "tiendas principales", definidas como "lujosos establecimientos en los cuales se venden las telas más ricas y las confecciones más costosas de las fábricas europeas y asiáticas". ${ }^{26}$

La primera gran tienda instalada en la ciudad de Buenos Aires fue A la Ciudad de Londres, propiedad de los hermanos Jean y Hugo Brun, de nacionalidad inglesa. Este negocio dio sus primeros pasos hacia 1872 con el nombre Salones Argentinos, cuyo pequeño local se ubicaba en la emblemática calle Florida, vía comercial por excelencia que hasta el día de hoy mantiene su carácter comercial. Posteriormente, en 1876 se trasladaron a un gran edificio situado en la esquina de las calles Perú y Victoria, a pocas cuadras de la Plaza de Mayo, centro neurálgico

21. Fernando Rocchi, Chimneys in the Desert. Industrialization in Argentina During the Export Boom Years, 1880-1930 (California: Stanford University Press, 2006) 16-48.

22. Leach, Land of Desire 45.

23. David Harvey, París, capital de la modernidad (Madrid:Akal, 2008) 271-283.

24. Sennett 179-181.

25. Adolfo Dávila y otros, dir., Censo general de población, edificación, comercio e industrias de la Ciudad de Buenos Aires, t. 2 (Buenos Aires: Compañía Sud-Americana de Billetes de Banco, 1889) 220.

26. Dávila y otros 221. 
de la ciudad; allí "levantaron los cimientos de la ya célebre tienda La Porteña, cuyo propietario, el señor Arnal, había fallecido hacía poco tiempo en Francia”. ${ }^{27}$ Así nació A la Ciudad de Londres, "primera casa de ventas de Buenos Aires montada al estilo del Louvre y el Bon Marché de París", ${ }^{28}$ cuya popularidad fue creciendo gracias "a su sistema de ventas y a una perfecta organización”. ${ }^{29}$ Para 1880, A la Ciudad de Londres constituía uno de los negocios más importantes de la ciudad, que ya contaba con 112 empleados y más de 100 modistas y bordadoras externas. ${ }^{30}$ La gran tienda ofrecía géneros, pero también, ropa hecha y, del mismo modo, prometía en algunos avisos confeccionar a medida vestidos o trajes y entregarlos en 48 horas. ${ }^{31}$ Así, este tipo de establecimientos combinaba comercio y producción, es decir, a la venta de telas y otros artículos importados de Europa se sumaban las prendas de vestir confeccionadas en talleres propios, según modelos europeos.

El suplemento que La Nación publicó en 1910 en ocasión del Centenario subraya la envergadura de este negocio, cuyo origen modesto, con tan solo siete empleados, había dado lugar a un creciente número de productos, empleados y clientes, cifras que se incrementaban aún más en determinados momentos del año: "de vez en cuando, con motivo de las grandes exposiciones de principio y fin de estación, la avalancha de compradores en sus movimientos afanosos de vaivén, acentúa el prestigio del establecimiento, que adquiere el aspecto de una romería o una gran feria". 32

Al igual que las grandes tiendas europeas, A la Ciudad de Londres adquirió la práctica de venta a precio fijo, lo que constituyó "toda una revolución en nuestro mundo femenino, acostumbrado al interminable regateo de antaño"; 33 la cual estuvo acompañada por el novedoso sistema de devolución de compras. Estas innovaciones aumentaban la sensación de "buena fe", poderosamente auxiliada por una propaganda eficaz hasta entonces desconocida: "La publicidad entró de moda y A la Ciudad de Londres le ha valido la extensión de su clientela hasta el último rincón de la República". ${ }^{34}$ El reclamo publicitario se dirigía a un público variado y heterogéneo: "allí hay de todo, de todos los gustos, de todos los precios, para gente rica, para gente acomodada, para gente pobre". 35

La instalación de grandes tiendas representó lo moderno frente a prácticas comerciales que venían desapareciendo, transformaciones que provocaban cierta

27. La Nación, suplemento especial en ocasión del Centenario (Buenos Aires) 25 de mayo de 1910: 186.

28. La Nación 186-187.

29. La Nación 186-187.

30. Hilda Sábato y Luis Alberto Romero, Los trabajadores de Buenos Aires, la experiencia del mercado. 1850-1880 (Buenos Aires: Editorial Sudamericana, 1992) 59.

31. Es el caso de los dos avisos publicados en El Mosquito que citamos en el presente trabajo: El Mosquito (Buenos Aires) 3 de octubre de 1880 y El Mosquito (Buenos Aires) 1 de octubre de 1882.

32. La Nación 187.

33. La Nación 187.

34. La Nación 187.

35. La Nación 187. 
nostalgia por las tradicionales dinámicas de compra y venta. Ejemplo de ello son las reflexiones que hacia 1884 realizaba el novelista Lucio Vicente López:

Las tiendas europeas de hoy, híbridas, sin carácter local, han desterrado la tienda porteña de aquella época [...] ¡Oh, qué tiendas aquellas! Aquella era buena fe comercial y no la de hoy, en la que la enorme vidriera engolosina los ojos sin satisfacer las exigencias de tacto que reclamaban nuestras madres con un derecho indiscutible [...] Cuando las lindas transeúntes penetraban a la tienda, el dueño dejaba a sus amigos, saludaba a sus clientas con un efusivo apretón de manos, preguntaba a la mamá "por ese caballero", echaba algunos requiebros de buen tono a las señoritas, tomaba mate de manos del cadete y lo ofrecía a las señoras con la más exquisita amabilidad. ${ }^{36}$

El vínculo entre el dueño de la pequeña tienda, que conocía a sus clientas, las saludaba amablemente cuando entraban al negocio y hasta les ofrecía un mate, contrasta con la despersonalizada relación que establece el cliente de la gran tienda con alguno de los empleados con quienes no podía instaurar una comunicación personal, ni regatear precio alguno. Así, esta experiencia de consumo no solo era más moderna, sino también más urbana y anónima. El precio de los productos, establecido de antemano y escrito en una tarjeta colocada en el artículo, representó la antítesis de la lucha verbal que otrora entablaran el tendero y la dama de Buenos Aires: "él pedía el doble de su valor por el género que proponía en venta, y ella le ofrecía la mitad de lo que estaba dispuesta a dar, y después de grandes concesiones de parte de vendedor y compradora, el trato se cerraba por un precio bien distinto del primitivo, del de la demanda y del de la oferta". ${ }^{37}$ Las grandes tiendas también introdujeron la posibilidad de comprar a crédito y recibir las compras en el domicilio.

La inauguración de otras tiendas departamentales como Gath \& Chaves (1883), Tienda San Juan (1887) y A la Ciudad de México (1889) da cuenta de la consolidación que este tipo de comercios tuvieron en Buenos Aires antes de la crisis de 1890. ${ }^{38}$ Para 1887, por ejemplo, del total de 33,904 empleados de comercio que se censaron en Buenos Aires, el 53\% se desempeñaban como dependientes de estas grandes tiendas. ${ }^{39}$ Si bien la crisis de 1890 implicó pérdidas económicas, todas ellas pudieron recuperarse y ya para el cambio de siglo se encontraban fuertemente instaladas en la ciudad, al punto de que Sir W. Burbidge decidió en 1914 inaugurar una sucursal de la londinense Harrods, la única que abriría sus puertas fuera del continente europeo.

36. Lucio Vicente López, La gran aldea (Buenos Aires: Capital Intelectual, 2010) 22.

37. Dávila y otros 222 .

38. Susana Saulquin, Historia de la moda argentina. Del miriñaque al diseño de autor (Buenos Aires: Emecé, 2006) 64-65.

39. Saulquin 231. 


\section{Construyendo al consumidor: los avisos comerciales y la publicidad de las grandes tiendas}

Consumir es una práctica multifacética en la que confluyen lo económico, lo social y lo cultural. En este marco, la publicidad, fenómeno asimismo complejo, requiere un abordaje que trascienda el análisis de estrategias de venta y permita una mirada sociocultural. ${ }^{40}$ En esta línea se sitúan los trabajos de Paula Félix-Didier y Sandra Szir en torno a la publicidad de los magazines modernos, especialmente la célebre Caras y Caretas, publicación del tipo "semanario de variedades". ${ }^{41} \mathrm{Su}$ publicidad fue, asimismo, objeto del análisis de Ana Moraña. ${ }^{42}$ En tanto la publicidad conforma un discurso social, las herramientas de la sociolingüística que María Soledad Pessi utiliza para analizar la publicidad de la prensa argentina moderna resultan convenientes para un abordaje sociocultural del fenómeno publicitario. ${ }^{43}$

Desde los primeros periódicos coloniales publicados en Argentina hasta los que vieron la luz a mediados del siglo XIX, los avisos comerciales no eran más que anuncios que informaban hechos novedosos. Estos avisos de tipografia uniforme, que ocupaban generalmente la última página del periódico, corresponden a la modalidad publicitaria tradicional. Es en la década de 1860 que aparecen los avisos modernos, entendidos como estrategias del productor para reducir el poder de persuasión del comerciante. ${ }^{44}$ Mientras los clasificados tradicionales eran leídos solo por las personas que buscaban determinado producto o servicio, los avisos modernos procuraban llamar la atención de todos los lectores, tomarlos desprevenidos e intentar, por ese medio, persuadirlos de comprar productos. Entre las estrategias que se despliegan en esta nueva publicidad destacan las diferentes tipografias y tamaños de letra, así como las imágenes que cada vez ganan mayor espacio, la

40. Entre los referentes de la historia sociocultural de publicidad destacan los trabajos de Roland Marchand, Advertising the American Dream. Making Way for Modernity, 1920-1940 (Berkeley: University of California Press, 1985); Juliann Sivulka, Soap, Sex and Cigarettes: A Cultural History of American Advertising (Belmont: Wadsworth Publishing Company, 1998); Juliann Sivulka, Stronger Than Dirt: A Cultural History of Advertising Personal Hygiene in America, 1875 to 1940 (New York: Humanity Books, 2001); Daniel Delis Hill, Advertising to the American Woman 19001999 (Columbus: Ohio State University Press, 2002), y Jackson Lears, Fables of Abundance: A Cultural History of Advertising in America (New York: Basic Books, 1994).

41. Félix-Didier y Szir.

42. Ana Moraña, "La propaganda, la moda y el consumo en la revista Caras y Caretas (Argentina, 1898-1910)", Estudios 16.32 (2008): 249-273.

43. María Soledad Pessi, "Publicidades Patrióticas. Una fusión entre el fomento al consumo y los festejos del Centenario en la Argentina", La renovación de la palabra en el bicentenario de la Argentina. Los colores de la mirada lingüística, eds. Víctor M. Castel y Liliana Cubo de Severino (Mendoza: Editorial de la Facultad de Filosofia y Letras, Universidad Nacional de Cuyo, 2010) 1025-1033; María Soledad Pessi, “Tabú y publicidad. El titular en avisos publicitarios gráficos de productos para el período menstrual (1930-1955)”, Tonos. Revista Electrónica de Estudios Filológicos 19 (2010). http://www.tonosdigital.com/ojs/index.php/tonos/article/viewFile/411/289 (12/04/2018).

44. Rocchi, "Inventando la soberanía del consumidor" 302. 
referencia a "marcas" de productos que diferenciaban unos de otros y los mensajes que buscaban estimular el deseo y crear necesidades. Con el tiempo, la publicidad incorporaría técnicas de persuasión más sofisticadas, diversidad de diseños tipográficos, viñetas y recuadros. El desarrollo de ingeniosas prácticas persuasivas da cuenta de la creciente relevancia que la publicidad adquirió como herramienta de apoyo para la actividad comercial, especialmente en la novedosa tienda A la Ciudad de Londres que para captar o mantener cierto público fue modificando su lenguaje publicitario.

Analizar estos avisos permite conocer la oferta de productos, pero también las estrategias utilizadas para construir una clientela. Si todo discurso publicitario fue elaborado con un objetivo claro — vender-, resulta lógico que la publicidad refleje esas intenciones. Sin embargo, en cuanto productores de significados, los avisos buscan "reconstruir" partes de la realidad e involucran al lector desde el momento en que este participa de su interpretación. ${ }^{45}$

Como veremos, A la Ciudad de Londres difundía avisos de variado estilo y tamaño en los que hacía referencia a los "paquetes", cargamentos traídos de Francia e Inglaterra. En general, la publicidad aparecía en publicaciones de periodicidad semanal o quincenal; algunas tenían a las mujeres como principales destinatarias, mientras otras, con un alto contenido político y críticas a ciertos círculos sociales y a personajes de la vida pública, se dirigían a un público más heterogéneo y, probablemente, masculino. Analizaremos a continuación estos avisos comerciales buscando reconocer a quiénes iban dirigidos, qué información contenían, qué estrategias se desplegaron para atraer posibles clientes y cómo se fueron complejizando y enriqueciendo.

\subsection{Los primeros avisos}

Los primeros avisos de la gran tienda seguían las tendencias de la publicidad de la década de 1870, ya que eran del tipo tradicional, es decir, fundamentalmente informativos. Estaban organizados en dos grandes partes, por un lado, el título nombre de la tienda - en una tipografia mayor y, por otro, una larga enumeración de adminículos. En la revista La Perla encontramos la primera publicidad de A la Ciudad de Londres, la cual ocupa, aproximadamente, media página y enfatiza como principales atributos de la casa la variedad, la novedad y la exclusividad de los artículos importados disponibles:

Hoy la más vasta y la mejor surtida tienda de Buenos Aires, recibiendo los artículos de moda de los más recientemente creados por cada paquete de Francia e Inglaterra, primera casa en Buenos Aires, habiendo establecido sistema de vender todo de confianza y a precio fijo, lo que le ha valido un éxito inigualable hasta hoy. Calle Perú 32, 34, 38 y 40. [...] Especialidades: Sederías negras; sederías de colores; sederías blancas para casamiento, única especialidad en Buenos Aires;

45. Dussaillant 239. 
confecciones para señoras y niñas; vestidos hechos y tapados, desde la clase más acomodada hasta los artículos más ricos $[\ldots]$ juegos de servilletas y manteles blancos de hilo; pañuelos $[\ldots]$ ropa blanca para señoras y niñas; medias francesas [...] corbatas, un millón, desde 5 pesos hasta $100 .{ }^{46}$

Un año después, en El Cosmopolita encontramos publicidad que, además de informar la ubicación de la tienda y la procedencia de los productos, asociaba la compra con días o períodos particulares dentro del calendario:

Fiestas mayas. Estación de invierno de 1879. Avisamos a nuestras favorecedoras [...] que los surtidos recibidos en provisión de la estación actual, son los más completos que se puedan desear. Como siempre hemos reunido las novedades más recientemente creadas, las más de moda, y las ofrecemos a nuestras favorecedoras desafiando toda clase de competencia.Ya sea en vestidos hechos, tapados y confecciones de todas clases para señoras y niñas [...] Ninguna casa puede ofrecer hoy un surtido tan completo a precios tan cómodos a como el que se encuentra. ${ }^{47}$

La oferta de artículos es considerablemente mayor respecto de aquello que la tienda ofrecía solo un año antes. Se enfatizan las confecciones que la tienda realiza y se ofrece una descripción de los distintos tipos de géneros y telas que se pueden encontrar en la tienda. En agosto del mismo año el texto se renueva, se vuelve aún más largo y detallado. ${ }^{48}$ Aquí, la publicidad especifica el stock de novedades haciendo uso de distintas tipografias y tamaños de letra. Pero lo novedoso de este aviso, en relación con los precedentes, es la frase: "Aviso a las señoras", mediante la cual se especifica el tipo de clientes que está buscando la tienda: mujeres.

La naturalización del vínculo mujer-moda-consumo venía consolidándose hacía tiempo. Aun cuando los hombres aristocráticos del siglo XVIII europeo, especialmente en Francia, se presentaban tan adornados como las mujeres, eran estas representadas como "frívolas" y "naturalmente" afectas a las modas. ${ }^{49}$ De igual forma, en la España del siglo XVIII circularon escritos que amonestaban a las mujeres por el "desmedido" consumo de prendas y adornos de moda, práctica que atentaba contra la estabilidad económica del hogar, cuyo proveedor era el hombre. ${ }^{50}$ Esta representación de la mujer, cuya esencia era la inclinación a las "frivolidades", tuvo una impronta tan fuerte que continuó reproduciéndose en el tiempo y el espacio; tan es así, que en la moderna publicidad de finales del siglo XIX se apela a la mujer como principal consumidora de telas y vestidos. La publicidad reproducía

46 La Perla (Buenos Aires) 1 de agosto de 1878:16. Se repite en los números de septiembre, octubre y noviembre. Luego, la revista baja su frecuencia y la publicidad de esta tienda recién vuelve a aparecer en mayo de 1879, y ocupa casi toda la página. El aviso, idéntico al citado, se repite hasta agosto de 1879, último número disponible de esta publicación.

47. El Cosmopolita (Buenos Aires) 8 de mayo de 1879: 11. Se repite en todos los números de mayo, junio y julio.

48. El Cosmopolita (Buenos Aires) 14 de agosto de 1879: 12.

49. Christine Bard, Historia política del pantalón (Buenos Aires:Tusquets, 2012) 11-19.

50. Discurso sobre el luxô de las señoras, y proyecto de una trage nacional (Madrid: Imprenta Real, 1788) 9-27. 
discursos que perpetuaban esas representaciones y, así, la imagen de la mujer consumidora convivirá con la imagen de la mujer bella y la mujer madre a partir de la promoción de variados productos. ${ }^{51}$

En 1879, en ocasión del año nuevo que se acercaba, A la Ciudad de Londres publicó un aviso que ofrecía los "Aguinaldos, etrennes o regalos para el año $1880 ",{ }^{2}$ allí se ofrecía vasta información sobre los productos a la venta: por un lado, la sedería; por otro las confecciones; luego, los géneros para vestidos y, por último, las "especialidades". Se insiste en el stock disponible y en su constante renovación, lo que denota el carácter fugaz de la moda y el esfuerzo de la tienda por "mantenerse al día" respecto de las tendencias internacionales. Lo nuevo como criterio central de asignación de valor estético data de comienzos del siglo XIX, se extiende más allá del ámbito de la moda y alcanza los espacios políticos e ideológi$\cos { }^{53}$ Del mismo modo, los avisos procuraban acomodarse a momentos específicos del calendario y, así, cada ícono temporal — la llegada de una nueva estación, de la pascua o del año nuevo — se volvía una excusa para incitar a la compra.

Los avisos iban dirigidos a un público socialmente diverso, pues tal como reza el siguiente anuncio publicado en El Cosmopolita se ofrecía "lo más elegante" y, a la vez, "lo más económico".

Las sederías de 'A la ciudad de Londres' salen de las mejores fábricas francesas, son garantidas al uso y desafiamos toda competencia por su baratura y clase" [...] Ninguna casa puede competir con el surtido que hemos recibido, sea en gustos, clases o precios. ${ }^{54}$

Aquí se enfatizan dos cualidades que podrían pensarse contradictorias: elegancia y bajo precio. Esta idea de "lujo democratizado" que habría llegado a las sociedades modernas por la vía de las grandes tiendas implicó que aquellos productos que antes solo se encontraban en pequeños negocios exclusivos ahora eran, o al menos parecían, accesibles a todos aquellos que entraran a la tienda. ${ }^{55}$ Esta singular combinación de refinamiento y asequibilidad apuntaba a un amplio y diverso público, pero, especialmente, a los sectores medios aún en formación, que tenían como grupo de referencia a la alta sociedad. ${ }^{56}$

Con el paso del tiempo, la tienda no solo ofrecería telas, sino crecientes volúmenes de prendas terminadas. Es probable que, con el objetivo de mantener el precio módico de los vestidos, se importaran géneros de Europa y se confeccionaran las

51. Ángeles Feliu Albaladejo y Dolores Fernández Poyatos, "La mujer en la publicidad. Hacia nuevos discursos", Actes de Congènere: la representació de gènere a la publicitat del segle XXI (Girona: Universitat de Girona, 2009).

52. El Cosmopolita (Buenos Aires) 18 de diciembre de 1879: 18.

53. Víctor Goldgel, Cuando lo nuevo conquistó América. Prensa, moda y literatura en el siglo XIX (Buenos Aires: Siglo XXI, 2012) 49-50.

54. El Cosmopolita (Buenos Aires) 18 de diciembre de 1879: 18.

55. Lancaster 16.

56. Hora y Losada 611-630. 
prendas en talleres de Buenos Aires, para luego ser ofrecidas al público como "productos europeos". Al no existir obligación de especificar el lugar de confección, la "moda europea" ofrecida podía referirse a las materias primas y no específicamente a la manufactura. A su vez, era habitual que se contrataran bordadoras y costureras francesas, ${ }^{57}$ lo cual también otorgaba "europeidad" a la ropa confeccionada localmente. De esta manera, "nuevo" y "europeo" eran las cualidades que otorgaban distinción a la prenda de vestir y, en consecuencia, a la persona que la llevara.

\subsection{La llegada de las imágenes: el caso del periódico El Mosquito}

En contraste con las exhaustivas descripciones propias de los avisos que venimos observando, hacia 1880, el periódico satírico El Mosquito exhibe un nuevo estilo publicitario que explota intensamente el uso de la imagen. Fundada en 1863, esta revista será pionera en la introducción de avisos comerciales con alta carga visual. ${ }^{58}$ De las tres páginas que componían El Mosquito, la publicidad de A la Ciudad de Londres ocupaba una completa. Los dibujos publicitarios seguían el mismo estilo que los del resto de la publicación, por lo que entendemos que quienes producían las imágenes para el cuerpo de la revista eran los mismos que ilustraban la publicidad; más aún, algunos avisos llevaban la firma de Henri Stein, fundador y dibujante estrella de El Mosquito. ${ }^{59}$ Asimismo, se observa cierto repertorio visual donde determinados elementos resultan recurrentes en diferente publicidad, aunque no se refirieran al mismo producto o negocio. ${ }^{60}$

La publicidad que sigue (Figura 1) está compuesta por texto e imagen en la que se pinta una escena que tiene en primer plano dos figuras masculinas, probablemente, los Hermanos Brun, abriendo un baúl, es decir, un "paquete" llegado de Europa. Uno de los personajes sostiene la tapa de la caja que reza en su interior “Tienda A la Ciudad de Londres. Primavera 1880", mientras el otro hombre extrae de la caja sombrillas, abanicos, guantes y otros accesorios que va depositando en el suelo. La imagen expresa una situación dinámica: se está abriendo la caja con mercaderías en ese momento, se están desplegando los productos recién llegados. Los artículos, pues son nuevos (acaban de llegar) e importados (llegan en un "paquete").

Con diferentes tamaños y tipografias se destacan algunas ideas: el nombre de la tienda, por ejemplo, es lo que abre y cierra el texto y en el centro aparece la referencia a un momento particular: la primavera de 1880. Es evidente que la moda construye su propia temporalidad que es, a su vez, la que define el carácter novedoso de

57. Sábato y Romero 59.

58. Para una historia de esta publicación véase Claudia Román, Prensa, política y cultura visual. El Mosquito (Buenos Aires, 1863-1893) (Buenos Aires: Editorial Ampersand, 2017).

59. Román 130-153.

60. Véase, por ejemplo, la publicidad del comercio Au Merinos de marzo de 1870 en la cual aparecen seres alados similares a los que podemos observar en la publicidad de A la Ciudad de Londres. Román 135. 
las prendas y accesorios. ${ }^{61}$ Además, el texto destaca el carácter variado de lo ofrecido con las frases "todos los ramos" y "surtido" y enfatiza la modalidad moderna de venta: "precios fijos" y "competencia". Asimismo, en la parte inferior se añade con letra de corto tamaño información que sigue un formato similar a los avisos tradicionales, esto es la enumeración y especificación de una serie de productos.

En su análisis del vestido femenino, según aparece en las revistas de moda, Barthes introduce las principales funciones del lenguaje (el vestido-escrito) en relación a la imagen (vestido-imagen). Las funciones del lenguaje son cuatro: inmovilización de los niveles de percepción, conocimiento, énfasis y descripción. ${ }^{62}$ En la publicidad que nos interesa, entendemos que el texto se ocupa de inmovilizar los niveles de percepción y enfatizar algunos conceptos. Dado que toda imagen conlleva varios niveles de percepción, es decir, que el lector goza de cierta libertad interpretativa, decide el sentido que le otorga a la imagen, el lenguaje viene a suprimir esa libertad cuando fija los mensajes que se están transmitiendo. De esta manera, la escena de los hombres abriendo el paquete podría ser percibida e interpretada de múltiples formas, si no fuera por el texto que le sigue y limita las posibles interpretaciones. El texto a su vez enfatiza la idea de la imagen con el uso de las frases "últimas novedades"; "mercaderías de estación”; "surtidos nuevos". A su vez, la temporalidad intrínseca de la moda manifiesta en la leyenda: "Primavera 1880", que leemos en la tapa interna de la caja, es uno de los mensajes destacados del texto.

La siguiente publicidad aparece en abril de $1881 \mathrm{y}$, si bien conserva un mismo estilo en las gráficas y los grabados, tiene características diferentes: se trata de un "prospecto" con ilustraciones, descripciones y, en ocasiones, el precio de los productos, los cuales aparecen organizados y clasificados en vestidos, tapados, sombreros, mantillas españolas, ropa blanca, guantes, artículos de tocador, ajuares para bebés, abanicos y artículos de perfumería. Este aviso subraya la variedad, novedad, buen gusto y precio conveniente de los artículos ofrecidos. Al ofrecer "lo mejor", "lo más completo", "lo más de moda", a la vez que lo más económico, la tienda apuntaba a construir a su público consumidor: sectores medios que en esta época perseguían un estilo de vida similar al de la alta sociedad. Cabe señalar que, si bien las mujeres de la alta sociedad tenían la posibilidad de viajar a Europa y adquirir allí parte de sus prendas, también concurrían a la gran tienda. Esa era una manera de mantenerse al tanto de una moda que cambiaba con cada estación. Así, el público al que la publicidad de A la Ciudad de Londres apuntaba era amplio, heterogéneo y cambiante, compuesto no solo por los sectores medios, sino también por los más encumbrados.

En los años siguientes se despliega como estrategia para atraer clientas la publicidad tipo "invitación personal", como una forma de vínculo directo con ellas:

61. Cabe señalar que aquello que en América Latina se presentaba como novedad, pertenecía a la temporada de verano europea que estaba finalizando.

62. Roland Barthes, "El Sistema de la moda", El Sistema de la moda y otros escritos (Buenos Aires: Paidós, 2008) 29-34. 
Figura 1. Aviso publicitario de la tienda A la Ciudad de Londres de 1880

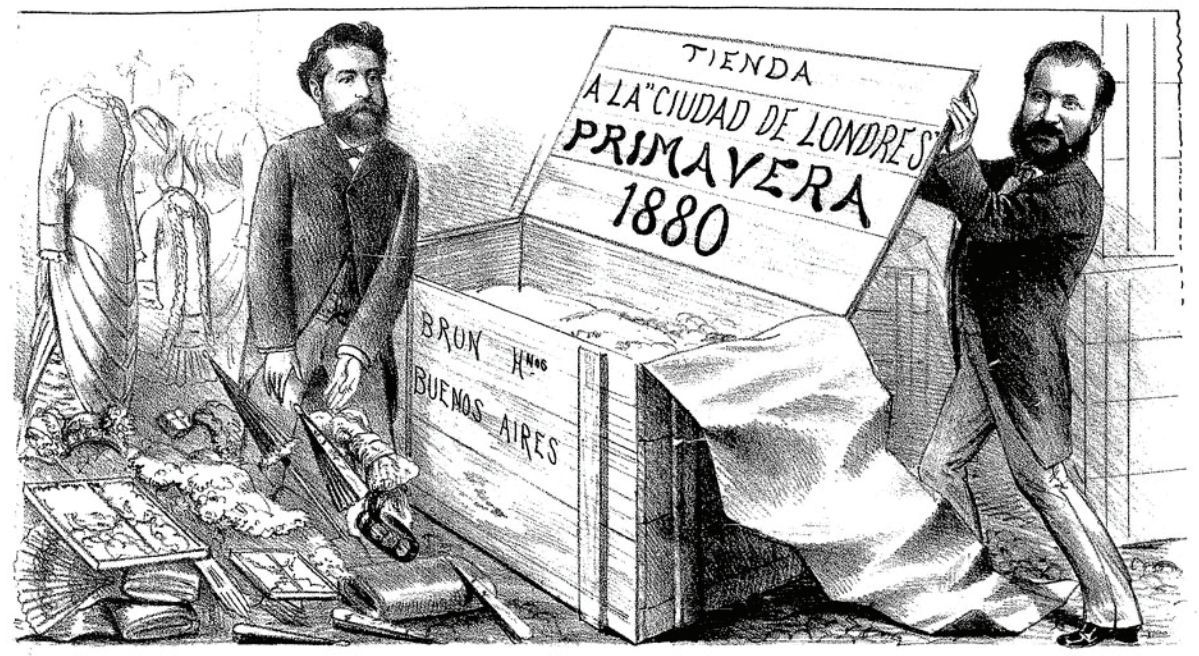

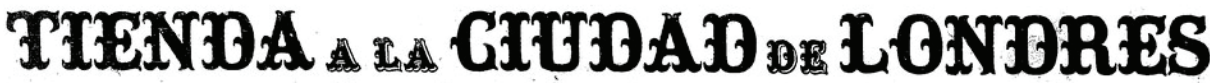

DXPOSICION GENBRAL

DE $L A 8$

HOY LA MAS VASTA Y IA METOR SURTHA DE BUBNOS AIRRS

Recibiendo los artículos de moda los más recientemente creados, por cada paquete de Francia é Inglaterra. Primera casa en Buenos Aires, habiendo establecido el sistema de vender todo de confianza y á precio fijo, lo que le ha valido un éxito sin igual hasta hoy.
DLTHIISS NOVRDADES

$\mathrm{xa}$

TODOS LOS ARTICULOS

TOILETTE

SURTIDOS NUEVOS

so

TODOS LOS RAMOS

Ds

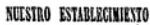

CALLE DEL PERU, 30, 32, 34, 38 y 40 Entrada unica: P畾 38

ENTRE RIVADAVIA Y VICTORIA

\section{PRIMAVERA DE 1880}

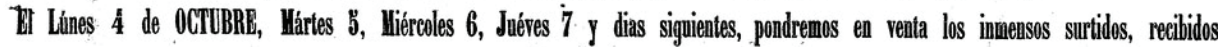
en prevision de la estacion actual:

A continuacion damos un Catalogo reduoido de algunos de los principales attioulos que estardn en venta los dias indicados.

Confecciones para señoras, Matinées para señoras, Batones para señoras, Tapados y confecciones para señoras, para niñas y señoritas, para criaturas, Vestidos ó costumes de luto y medio luto, Sederias, ocasion verdadera, Granadinas, Gasillas, Tules de seda y crespon, Manfi Corbatas, Luto y medio huto, Generos para vestidos, Genero de hilo para uso de familia, Generos de algodon blancos, Cortinas bordadas, Géneros para muebles, Corsées finos, Ropa blanca, lenceria y articulos de toilette para señoras y señoritas, Cuellos de moda para señoras, Ropa blahca para niñas y señoritas, Modas, Boneteria, Guanteria, Sombrillas, Abanicos, Merceria, Encages, Perfumeria, Artículos de fantasía para regalos.

NOTA. - Cada articulo lleva una etiqueta con indicacion de precios, y se vende á precio fijo.

OTRA. - Los tapados ó confeccioncs, si hay necesidad de arreglarlos al talle de las personas, lo mismo que los vestidos hechos para sentoras y sentoritas, lo hacemos sin aumento de precio, cualquiera que sea la clase del objeto comprado. Todos los articulos espresados, j otros gae nos es imposible enumerar, visto su estension, estaridn prestos en venta los dias arriba indicedios.

A La GIUDAD de IOINDEES 38, CALLE PERÚ, 38, ENTRE RIVADAVIA Y VICTORIA

Fuente: El Mosquito (Buenos Aires) 3 de octubre de 1880. 
Figura 2. Aviso publicitario de la tienda A la Ciudad de Londres de 1882

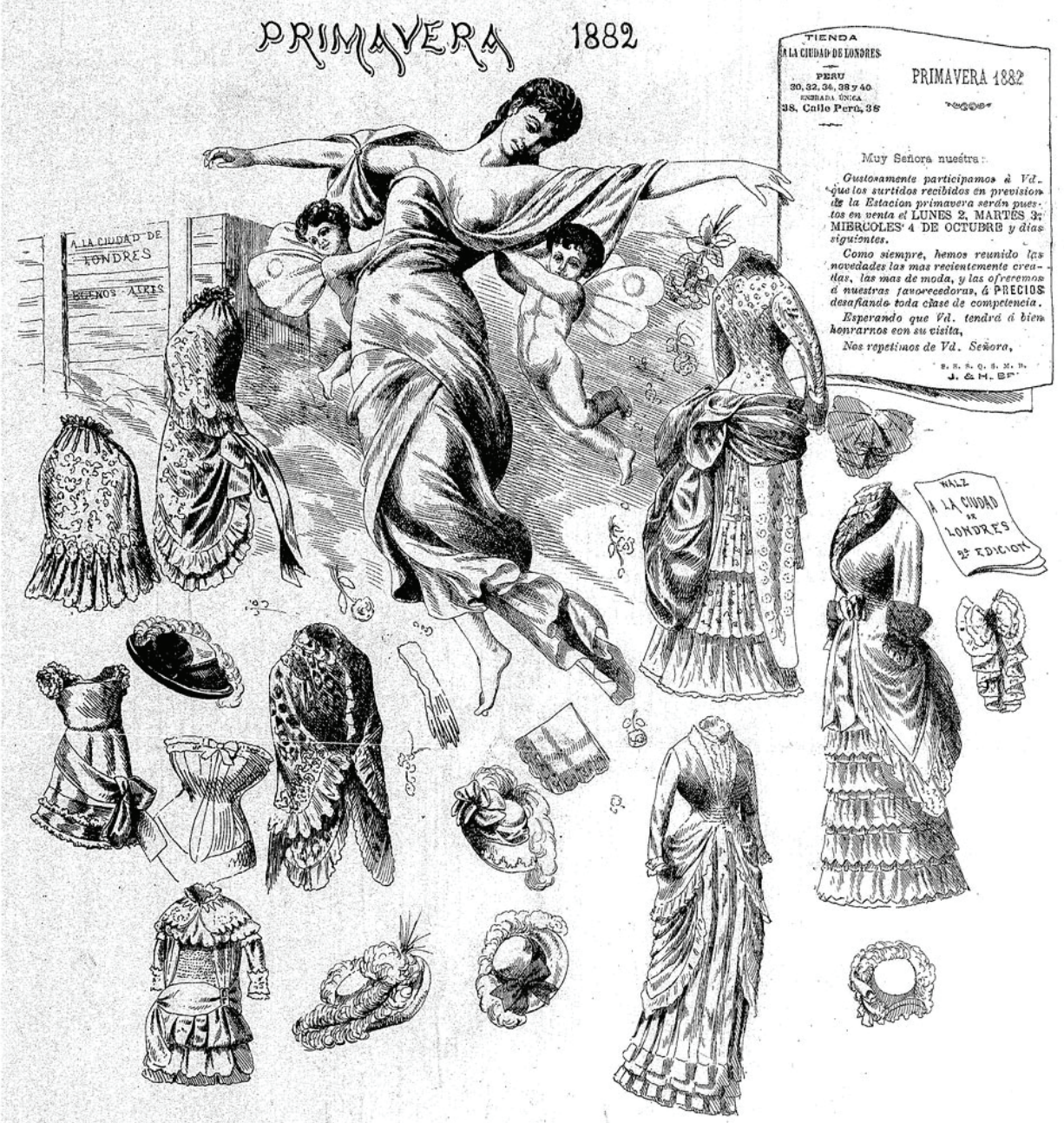

\section{TIFWDA "A LA CIUDAD DE LONDPES"}

Hoy la mas vasta y la mejor surtida de Buenos Aires recibiendo los artlculos de moda los mas recientemente creados, por cada paquete do FRANCIA é ING LATERRA. Primera casa en Buenos Aires habiendo establecido el sistema de vender todo de confianza y a precio fífo lá que le ha valido un exito
sinigual hasta hoy. PERÚ 30, 32, 34, 38 y 40 - Entrada única : 35, PERÚ, 38

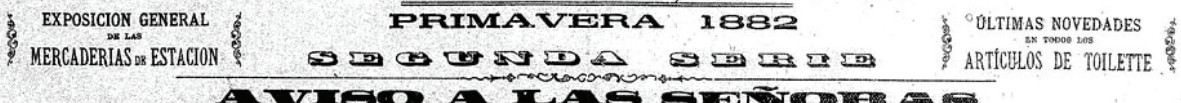
LA SEGUNDA SERIE de nuestras Mercaderias de PRIMAVERA HA LLEGADO: hemos recibido mas de quinientos cajones de Electos de todas Gustosamente avisamos a nuestras favorecedoras que la mayor parte de los articulos recibidos estarán puestos en venta el LUNES 2 de Octubre MARTES 3 , MIERCOLES 4 , JUEVES 5 Y DIAS SIGULIENTES. - Nunca hemos reunido UN SURTIDO TAAN COMPLETO, TAN YARIADO, TAN
ELEGANTE Y A PRECIOS TAN COMODOS como el que pondremos en venta los dias arriba indicados. Tienda á la Ciudad de Londres - PERÚ, 38 - Entre Rivadavia y Victoria

Fuente: El Mosquito (Buenos Aires) 1 de octubre de 1882. 
Invierno de 1882. Muy señora Ntra. Gustosamente participamos aVd. Que los surtidos recibidos en previsión de la Estación primavera serán puestos en venta el lunes 2, martes 3, miércoles 4 de mayo y días siguientes. Como siempre, hemos reunido las novedades las más recientes, las más de moda, y las ofrecemos a nuestras favorecedoras a precios desafiando toda competencia. Esperando queVd.Tendrá a bien honrarnos con su visita. Nos repetimos de Vd. Señora. ${ }^{63}$

Esta modalidad vuelve a repetirse en ediciones posteriores en las que se reduce el volumen de texto y predomina la imagen. En el aviso que sigue (Figura 2), referido a la primavera de 1882, observamos en el sector superior izquierdo el aludido baúl de madera con el nombre de la tienda, referencia a la importación de los artículos. En el centro reconocemos una mujer en pose etérea y sensual, con los brazos en cruz, sostenida por dos seres - niños - que guardan cierto parecido con figuras angelicales (querubines), aunque sus alas son semejantes a las de las mariposas. Este elemento pictórico (las alas de mariposa) sugiere una posible alusión a Psique, mítico personaje femenino de extraordinaria belleza, habitualmente representado con alas de mariposa, concreta alusión a su carácter bello, así como frágil y efímero. ${ }^{64}$ Por otra parte, la mariposa es una típica figura de las vanitas, ${ }^{65}$ junto con los consabidos componentes que aluden a la muerte (calavera) y a los placeres terrenales (dinero, bienes, juego, amores), además de la presencia de un ser angelical, ${ }^{66}$ cuyas alas en ocasiones se asemejan, precisamente, a las de las mariposas. ${ }^{67}$ Estas observaciones nos permiten pensar la imagen publicitaria como una confluencia de lo bello, lo vano y lo efimero que rodean y sostienen a una mujer cuyo cuerpo parece estar dormido, pasivo, sin movimiento, ¿rendido frente a la belleza y fugacidad de la moda? A todo esto, es el cuerpo femenino otro de los protagonistas de la escena. Semicubierto por capas de tela que no llegan a formar un vestido, en él predominan las líneas curvas. La postura lánguida de sus pies, junto a la ausencia de un suelo, sugiere que está flotando en el aire en una posición de inactividad, solo elevada por intermediación de los seres alados. Esta representación alimenta y reproduce el imaginario sobre la pasividad y debilidad femenina, asimismo, presente en otras imágenes pictóricas de la época. ${ }^{68}$ Finalmente, se presentan,

63. El Mosquito (Buenos Aires) 30 de abril de 1882: 3.

64. María Isabel Rodríguez López reconoce que la simbología del tema (la historia de amor entre Psique y Eros) tiene amplias posibilidades expresivas y puede ser susceptible de diversas interpretaciones. Así, el mito fue continuamente recreado en la pintura, la literatura y la música. María Isabel Rodríguez López "Omnia vincit Amor: iconografía de Eros y Psique", Cuadernos de Arte e Iconografía 11.21 (2002): 77-102.

65. La vanitas o vanidad es un género pictórico cuyo significado equivale a la vanidad de las glorias, los placeres y, en general, todo lo que se aprecia en este mundo, y responde al estilo ascético de la espiritualidad barroca.

66. Divinia Gómez Martín, Iconografía de la muerte en el arte moderno occidental (Trabajo de grado en Historia del Arte, Universidad de La Laguna, 2015) 18-20.

67. Ejemplo de ello es Vanitas de Jan Sanders van Hemessen.

68. Bram Dijkstra, Idols of Perversity: Fantasies of Feminine Evil in Fin-de-Siècle Culture (Nueva York: Oxford University Press, 1986). 
debajo de la mujer, prendas y accesorios de vestir: cuatro vestidos, un corsé, una falda, dos vestidos para niña y demás artículos: guantes, pañuelo, sombreros, tocados. Estos elementos, que refieren a productos factibles de encontrar en la tienda, aparecen "sueltos" sin seguir un orden específico, lo que refleja la intención de exhibir gran variedad y diversidad en el stock.

Si comparamos los avisos que la tienda publicaba en 1877 con este último, de 1882, podemos reconocer un negocio pujante, capaz de pagar costosos avisos en los que se desplegaban diversas estrategias para atraer clientes. El desarrollo de esta tienda implicó, sobre todo, una creciente diversificación de la oferta que incluía también artículos de toilette, sombreros, guantes, sombrillas, abanicos, perfumería, carteras, cristalería, juguetes, espejos, cepillos, álbumes de fotografias y un largo etcétera. Mientras la moda de la época se iba complejizando, la tienda se ponía a tono e iba mutando de negocio dedicado, casi exclusivamente, a la venta de telas a tienda de tipo departamental. Wayland Tonning relaciona la transformación de las pequeñas tiendas en tiendas departamentales en Illinois entre 1880 y 1890 con el aumento de población. ${ }^{69}$ En el caso de Buenos Aires, al crecimiento cuantitativo de habitantes se suma el cosmopolitismo de los mismos, una población no solo más numerosa, sino también más diversa, en la cual los crecientes sectores medios buscaban la mejora individual o familiar, compartían valores de impronta burguesa a la vez que aspiraban a imitar el estilo de vida de la alta sociedad.

\section{Conclusiones}

Buenos Aires en el último tercio del siglo XIX era un escenario pleno de transformaciones. La inserción de Argentina en el mercado capitalista mundial como productora de materias primas y alimentos, el mercado interno en franco crecimiento, el aumento de la población y su diversificación, de la mano de las oleadas inmigratorias, permitieron un despegue económico en la ciudad que fue adquiriendo, progresivamente, un aspecto cosmopolita y europeizado. En este contexto, el surgimiento de A la Ciudad de Londres, la primera tienda departamental de Buenos Aires, significó un antes y un después en el ámbito del comercio minorista de vestimenta. Sus características edilicias y estéticas, así como la implementación de la venta a precio fijo, habilitaron nuevas experiencias de consumo en las que no solo se intercambiaba dinero por producto, sino que se ingresaba a la tienda, se caminaba, se miraban y tocaban los artículos, se dialogaba con los vendedores u otros clientes y, finalmente, se compraba o no el producto. Abierta a todo público, aún a aquellos que no pudieran comprar, la tienda se constituyó en un certero espacio de sociabilidad y encuentro entre mujeres y entre personas de diferentes estratos sociales.

69. Wayland A. Tonning, "Department Stores in Down State Illinois, 1889-1943", The Business History Review 29.4 (1955): 335-349. 
Uno de los pilares de esta nueva forma de compra y venta fue la publicidad, estrategia de comunicación-persuasión mediante la cual los comerciantes atraían a sus clientes, pero, más aún, construían una clientela a la que destinaban sus productos. A lo largo del artículo analizamos la diferente publicidad de la emblemática tienda A la Ciudad de Londres; avisos que, con el tiempo, experimentaron transformaciones que los situaron en el ámbito de la publicidad moderna. En los primeros avisos detectamos un fuerte énfasis en la información, es decir, el detalle de los productos ofrecidos. En los avisos subsiguientes, en cambio, se diversifican tipografias y tamaños de letra junto a nuevas y variadas imágenes que van ocupando el lugar de las palabras.

Las detalladas imágenes que conforman la publicidad difundida por el periódico El Mosquito cuentan historias que tienen a las mujeres como protagonistas. Las mujeres aparecen como destinatarias de las "invitaciones personales" y son esencialmente prendas de vestir femeninas las que se describen en cada aviso. El relato publicitario de A la Ciudad de Londres construyó la clientela a quienes destinaba sus productos: mujeres. Asimismo, la publicidad parece apuntar a un público socialmente variado y heterogéneo, al que podemos identificar con los sectores medios. Al ofrecer lo más nuevo, exclusivo, elegante y europeo, pero al mismo tiempo lo más económico, la tienda proponía como clientes a aquellos que buscasen precisamente eso: "baratura y clase". Estos avisos dan cuenta no solo de cómo la publicidad fue un eje fundamental en la instalación y consolidación de este tipo moderno de negocio en Buenos Aires, sino que también constituyen indicios de algunas de las aspiraciones y ansiedades de aquella sociedad en plena transformación. Los sectores medios en crecimiento buscaban emular el cosmopolitismo de la alta sociedad de Buenos Aires que, sintomáticamente, buscaba alejarse de estas experiencias de consumo transcurriendo largas temporadas en París, donde generalmente adquiría sus prendas de vestir. ${ }^{70}$ Aunque contara con las posibilidades económicas para hacerlo, los cambios de vestimenta en cada temporada disminuían la posibilidad de mantener la actualidad en la apariencia deseada. Por ello, la burguesía también asumía a los grandes almacenes como alternativa de consumo. Así, la gran tienda con sus productos teóricamente europeos constituyó el espacio ideal para "hacer realidad" las aspiraciones de un heterogéneo conjunto social.

\section{Fuentes}

\section{Impresas}

Dávila, Adolfo y otros. Dirs. Censo general de población, edificación, comercio e industrias de la Ciudad de Buenos Aires. Tomo 2. Buenos Aires: Compañía SudAmericana de Billetes de Banco, 1889. 
Discurso sobre el luxô de las señoras, y proyecto de una trage nacional. Madrid: Imprenta Real, 1788.

Kunz, Hugo y Cía. Gran guía de la Ciudad de Buenos Aires. Buenos Aires: Hugo Kunz y Cía, 1885.

Vicente López, Lucio. La gran aldea. Buenos Aires: Capital Intelectual, 2010.

\section{Periódicos y revistas}

La Nación (Buenos Aires) 1910.

La Perla (Buenos Aires) 1878.

El Cosmopolita (Buenos Aires) 1879.

El Mosquito (Buenos Aires) 1880 y 1882.

\section{Bibliografía}

Bard, Christine. Historia política del pantalón. Buenos Aires: Tusquets, 2012.

Barthes, Roland. "El Sistema de la moda". El Sistema de la moda y otros escritos. Buenos Aires: Paidós, 2008.

Bunker, Steven B. “'Consumers of Good Taste': Marketing Modernity in Northern Mexico, 1890-1910”. Mexican Studies / Estudios Mexicanos 13.2 (1997): 227-269.

Devoto, Fernando y Marta Madero. Dirs. Historia de la vida privada en la Argentina. Tomo 2. Buenos Aires: Taurus, 1999.

Dijkstra, Bram. Idols of Perversity: Fantasies of Femenine Evil in Fin-de-Siècle Culture. Nueva York: Oxford University Press, 1986.

Dussaillant Christie, Jacqueline. Las reinas de Estado: consumo, grandes tiendas y mujeres en la modernización del comercio de Santiago (1880-1930). Santiago: Pontificia Universidad Católica de Chile, 2011.

Feliu Albaladejo, Ángeles y Dolores Fernández Poyatos. “La mujer en la publicidad. Hacia nuevos discursos". Actes de Congènere: la representació de gènere a la publicitat del segle XXI. Girona: Universitat de Girona, 2009.

Félix-Didier, Paula y Sandra Szir. "Ilustrando el consumo”. Comunicación presentada en el I Congreso Internacional de Teoría e Historia de las Artes del Congreso Argentino de Investigadores del Arte: Poderes de la imagen, Asociación de Amigos del Museo de Bellas Artes de Buenos Aires, 2001. Germani, Gino. Política y sociedad en una época de transición. Buenos Aires: Paidós, 1974. Goldgel,Víctor. Cuando lo nuevo conquistó América. Prensa, moda y literatura en el siglo XIX. Buenos Aires: Siglo XXI, 2012.

Gómez Martín, Divinia. Iconografía de la muerte en el arte moderno occidental. Trabajo de grado en Historia del Arte, Universidad de La Laguna, 2015.

Harvey, David. París, capital de la modernidad. Madrid: Akal, 2008.

Hill, Daniel Delis. Advertising to the American Woman 1900-1999. Columbus: Ohio State University Press, 2002. 
Hora, Roy. Historia económica de la Argentina en el siglo XIX. Buenos Aires: Siglo XXI, 2010.

Hora, Roy y Leandro Losada. “Clases altas y medias en la Argentina, 1880-1930. Notas para una agenda de investigación". Desarrollo Económico 50.200 (2011): 611-630.

Lancaster, Bill. The Department Store: A Social History. Leicester: Leicester University Press, 1995.

Leach, William R. Land of Desire. Merchants, Power, and the Rise of a New American Culture. New York:Vintage Books, Random House, 1993.

."Transformations in a Culture of Consumption. Women and Department Stores, 1890-1925”. The Journal of American History 71.2 (1984): 319-342.

Lears, Jackson. Fables of Abundance: A Cultural History of Advertising in America. New York: Basic Books, 1994.

Losada, Leandro. La alta sociedad en la Buenos Aires de la Belle Époque. Sociabilidad, estilos de vida e identidades. Buenos Aires: Siglo XXI, 2008.

Marchand, Roland. Advertising the American Dream. Making Way for Modernity, 1920-1940. Berkeley: University of California Press, 1985.

Moraña, Ana. "La propaganda, la moda y el consumo en la revista Caras y Caretas (Argentina, 1898-1910)". Estudios 16.32 (2008): 249-273.

Pessi, María Soledad. "Publicidades Patrióticas. Una fusión entre el fomento al consumo y los festejos del Centenario en la Argentina”. La renovación de la palabra en el bicentenario de la Argentina. Los colores de la mirada lingüística. Eds.Víctor M. Castel y Liliana Cubo de Severino. Mendoza: Editorial de la Facultad de Filosofia y Letras, Universidad Nacional de Cuyo, 2010. . "Tabú y publicidad. El titular en avisos publicitarios gráficos de productos para el período menstrual (1930-1955)". Tonos. Revista Electrónica de Estudios Filológicos 19 (2010). http://www.tonosdigital.com/ojs/index. $\mathrm{php/tonos/article/viewFile/411/289} \mathrm{(12/04/2018).}$

Prieto, Adolfo. El discurso criollista en la formación de la Argentina moderna. Buenos Aires: Editorial Sudamericana, 1988.

Rappaport, Erika D. “'The Halls of Temptation': Gender, Politics, and the Construction of the Department Store in Late Victorian London". The Journal of British Studies 35.1 (1996): 58-83.

Rocchi, Fernando. Chimneys in the Desert. Industrialization in Argentina During the Export Boom Years, 1880-1930. California: Stanford University Press, 2006.

. "Consumir es un placer: la industria y la expansión de la demanda en Buenos Aires a la vuelta del siglo pasado”. Desarrollo Económico 37.148 (1998): 533-558.

. "Inventando la soberanía del consumidor: publicidad, privacidad y revolución del mercado en la Argentina, 1860-1940”. Historia de la vida privada en la Argentina. Tomo 2. Dirs. Fernando Devoto y Marta Madero. Buenos Aires: Taurus, 1999.

Rodríguez López, María Isabel."Omnia vincit Amor: iconografia de Eros y Psique”. 
Cuadernos de Arte e Iconografía 11.21 (2002): 77-102.

Román, Claudia. Prensa, política y cultura visual: El Mosquito (Buenos Aires, 18631893). Buenos Aires: Editorial Ampersand, 2017.

Sábato, Hilda y Luis Alberto Romero. Los trabajadores de Buenos Aires, la experiencia del mercado. 1850-1880. Buenos Aires: Editorial Sudamericana, 1992.

Saulquin, Susana. Historia de la moda argentina. Del miriñaque al diseño de autor. Buenos Aires: Emecé, 2006.

Sennett, Richard. El declive del hombre público. Barcelona: Anagrama, 2011.

Sivulka, Juliann. Soap, Sex and Cigarettes: A Cultural History of American Advertising. Belmont: Wadsworth Publishing Company, 1998.

. Stronger Than Dirt: A Cultural History of Advertising Personal Hygiene in America, 1875 to 1940. New York: Humanity Books, 2001.

Szir, Sandra. "Discursos, prácticas y formas culturales de lo visual. Buenos Aires 1880-1910". Travesías de la imagen. Historia de las artes visuales en la Argentina. Volumen 1. Eds. María Isabel Baldasarre y Silvia Dolinko. Buenos Aires: Editorial de la Universidad Nacional del Tres de Febrero, 2011.

Tonning, Wayland A. "Department Stores in Down State Illinois, 1889-1943”. The Business History Review 29.4 (1955): 335-349. 